Recommendations Consensus on bilirubin chart to be used.

National survey to find out the number of exchange transfusions done in preterm infants.

\section{FETAL ANALGESIA AND BRAIN DAMAGE}

doi:10.1136/archdischild-2012-302724.1300

C Bellieni, G Buonocore. Pediatrics and Obstetrics, University of Siena, Siena, Italy

Aim Fetal surgery is increasingly performed in many centers. Nevertheless, in most cases, analgesic treatment is still absent with the risk of brain damage in the newborn, due to the sudden rise in blood pressur and intracranial pressure due to pain. We performed a review on the present state of direct fetal analgesia, to show the importance to prevent pain and consequently newborns' brain damage in these cases.

Methods We performed a pubmed search to retrieve the research papers that reported studies of fetal surgery in the last 10 years, and in which a careful description of the type of analgesic treatment is reported.

Results We retrieved 38 papers, 3 of which did not sensibly hurt the fetus, being performed on fetal annexes, and 2 performed in the first trimester, when fetal pain is negligible. Of the 33 remaining papers, only 14 were performed using a direct fetal analgesia. No drawbacks were reported.

Conclusion Fetal direct analgesia though safe, is still performed only in less than half of cases. An implementation of its use is needed, to prevent brain damages in the newborns.

\section{EFFECT OF MYDRIATIC EYE DROPS ON CEREBRAL AND MESENTERIC TISSUE OXYGENATION IN VERY LOW BIRTH WEIGHT INFANTS; PRELIMINARY REPORT}

doi:10.1136/archdischild-2012-302724.1301

${ }^{1} \mathrm{H}$ Tatar Aksoy, ${ }^{1} \mathrm{SS}$ Oguz, ${ }^{2} \mathrm{Z}$ Özen Tunay, ${ }^{2} \mathrm{R}$ Yıldız, ${ }^{1} \mathrm{HG}$ Kanmaz, ${ }^{3} \mathrm{U}$ Dilmen. ${ }^{1} \mathrm{NICU}$, Zekai Tahir Burak Maternity and Teaching Hospital, Department of Neonatology; ${ }^{2}$ NICU, Zekai Tahir Burak Maternity and Teaching Hospital; '3ekai Tahir Burak Maternity and Teaching Hospital/YIldırım Beyazıt University Department of Pediatrics, Ankara, Turkey

Preterm infants weighing less than $1500 \mathrm{~g}$ routinely undergo a series of eye examinations to screen for retinopathy of prematurity (ROP). Mydriatic eye drops used for pupil dilatation while these examinations may be absorbed by nasopharyngeal mucosa and gastrointestinal system that may cause neurological and gastrointestinal side effects rarely. We aimed to evaluate the effect of mydriatic eye drops on cerebral and mesenteric tissue oxygenation by near infrared spectroscopy (NIRS), in very low birth weight (VLBW) infants. Eleven preterm infants with a gestational age of $<32$ weeks and/or birth weight $<1500$ gr were included the study. Infants with intracranial hemorrhage (>grade II), PDA, major congenital anomalies, major heart disease, infection, anemia, thyroid disease, acidosis, history of perinatal asphyxia and surgery, not feeding orally, were excluded the study. Cerebral and mesenteric tissue oxygenation were measured by NIRS probes that located forehead and umbilical region before and after the mydriatic eye drops. Eleven ( 6 female, 5 male) infants were included the study. The median gestational age, birth weight, postnatal age and body weight during examination were 29 weeks, 1190g, 39 days and $1700 \mathrm{~g}$, respectively. Before the mydriatic eye drops mean cerebral and mesenteric $\mathrm{rSO}_{2}$ were $63.0 \pm 7.6$ and $54.9 \pm 10.1$, respectively. After the eye drops mean cerebral and mesenteric $\mathrm{SO}_{2}$ were $60.0 \pm 10$ and $51.7 \pm 9.9$, respectively. Although the slightly decrease in oxygenation after mydriatic eye drops there were no statistically significant differences $(p=0.6$ and $p=0.1)$. We believe that this difference may reach statistically significant levels in large study population.

\section{EPIDEMIOLOGY OF LATE PRETERM INFANTS (LPI): SAUDI TERTIARY CARE FACILITIES EXPERIENCE}

doi:10.1136/archdischild-2012-302724.1302

${ }^{1}$ A Mersal, 'A Almahbosh, ${ }^{2} \mathrm{~B}$ Binsadeqe. 'Pediatrics; ${ }^{2}$ Research Center, King Faisal Specialist Hospital \& Research Centre, Jeddah, Saudi Arabia

Introduction and Background Late preterm infants (LPI) are born at a gestational age between 34 weeks and 36 weeks and 6 days. They have higher morbidity and mortality than term infants due to their relative physiologic and metabolic immaturity.

Method Infants born between July 2008 and July 2010 are identified using NICU and Labor and delivery registry of King Faisal Specialist Hospital-Jeddah. The deliveries are around 1100 births per year. The pertinent data of all mothers and neonates delivered at KFSH\&RC-J abstracted from medical records.

Results 230 infants' enrolled; incidence rate of LPI in the year 2008 was $6.7 \%, 2009$ was $5.7 \%$ and $12.07 \%$ in 2012, 101 female and 128 male, 167 (72.6) had no maternal risk factors, artificial reproductive technology $55 / 230(23 \%)$, maternal hypertension is $5 / 230(2.2 \%)$. PROM is $3 / 230$ ( $1.3 \%)$, no chorioamnionities or diabetes mellitus.

Cesarean sections $121 / 202(59 \%)$ in LPI, vs $200 / 392$ (51\%) in full term babies ventous delivery $2 / 202(1 \%)$ vs $7 / 392(1.8 \%)$.

Singleton vs. twin or triplet $59.7 \%$ vs. $28.7 \%$ or $11.6 \%$; the gravida the maternal age and gravida showed no difference; morbidity in LPI, respiratory distress syndrome 92/230 (40\%) hyperbilirubineamia required treatment $13 / 230$ (5.7\%), apnea $11 / 230$ (4.8\%), sepsis $21 / 230(9.5 \%)$, feeding problems $23 / 230$ (10\%), hospital readmission $8 / 230$ (3.5\%). Admission to NICU was $116 / 229$ (50\%).

Conclusion Our result is very comparable with previous other studies, however the mortality rate in our series is negligible, perhaps related to our aggressive management and early admission to NICU for 48 hours observation.

\section{EVOLUTION OF NEONATAL MORTALITY IN THE NEONATAL DEPARTMENT - IN KOUBA HOSPITAL - ALGIERS}

doi:10.1136/archdischild-2012-302724.1303

S Alhallak, A Elhasane. Kouba Hospital, Algiers, Algeria

Introduction Neonatal deaths account for a large proportion of child deaths.mortality during neonatal period (2/3-3/4 our countrie)considered a good indicator of both maternal and newborn health and care.

Perinatal mortality:defined as nombre of stillbirths and deaths in the first weekof lif per 1000 births.

Objective To study evolutionof the rate of perinatal mortality, and to analyze the causes of this mortality.

Aims and methods: Data sources:

Registery of delivery room and registery of neonatal department.

Descriptive retrospective study on file of the newborn hospitalized in the department of neonatology during 11 years $(1 / 1 / 2001$ to31/12 2011)

In (2004-2005): adaptation of the infrastucture, equipment by materiels, recruitment, stabitity of the medical personnel.

Results In 11 years 77099 births were recorded, among them 1569 stillbirths, a rate of global mortinatality of $20.35 \% 0$ in 2001 to $18 \% 0$ in 2006 to $15.2 \% 0$ in 2011 , the early neonatal mortalitywas $20.2 \% 0$ in 2001 to $13.6 \% 0$ in 2006 to $10.25 \% 0$ in 2011 . The perinatal mortality diminished from $50.6 \% 0$ in 2001 to $30.7 \% 0$ in 2006 to $25.3 \% 0$ in 2011.

The intra-hospital mortality lowered of $50 \%$, from $6.6 \%$ in 2001 to 3.48 in 2011 . She remained stable since 2007.

The causes of mortinatality by gravidic toxemia and its complications. The neonatal causes of deaths are dominated by exreme prematurity, DRS, asphyxia. The causes are often multiple and been interlinked. 
Conclusion Tthe improvement of these indicators is attributed to the improvement the conditions of woman; following, screening and the taken in charge of the high risk pregnancies. As well as the improvment of the taken in charge of the newborns in work-room.

\section{NEWBORN LOW BIRTH WEIGHT: MOROCCAN DATA}

doi:10.1136/archdischild-2012-302724.1304

'A Barkat, ${ }^{2} \mathrm{M}$ Banouar. 'Equipe de Recherche en Santé et Nutrition du Couple Mère

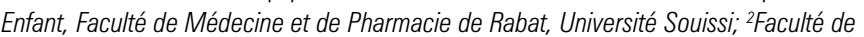
Médecine et de Pharmacie de Rabat; Université Souissi, Rabat, Morocco

Objective The overall objective of this work is to describe the prevalence of newborns with low birth weight in Rabat Souissi Maternity Hospital in 2010. The specific objective is to compare the population of preterm and small for gestational age, assess their immediate future and identify the causes.

Methods The study tok place at Rabat Souissi Maternity Hospital between January 1st 2010 and December 2010. Were enrolled, all newborns weighing $<2500 \mathrm{~g}$. The main variables collected were gestational age, sex, route of extraction, Apgar at $5 \mathrm{~min}$, the maternal age, parity, maternal disease history and immediate future of the newborn.

Results Of 14,808 live births registered during 2010, 1475 newborns had a birth weight less than $2500 \mathrm{~g}$ or $9.96 \%$ of which 722 were small for gestational age, 728 were premature infants. Vaginal delivery was predominant in both populations. The average age of mothers was $(28.22 \pm 6.83$ vs $28.63 \pm 6.60)$ years $(p=0.89)$. The main etiologies encountered were the maternal genitourinary infections for prematurity $(25.6 \%)$ while the main cause of low birth weight were gestational hypertension (11.7). As for becoming immediate mortality was about $11 \%$ in premature infants against $2 \%$ in small for gestational age. $(p<0.001)$. Hospital transfers were in the range of $46.2 \%$. The main indications were respiratory distress, infection, and perinatal asphyxia.

\section{FULL TERM NEONATAL ADMISSIONS IN A REFERRAL HOSPITAL}

doi:10.1136/archdischild-2012-302724.1305

BR Qandalji. Pediatrics, Ministry of Health, Amman, Jordan

Background and Aim Full term neonates represent a significant proportion of neonatal addmisions. The aim of this study was to see the characteristics of this group in the largest neonatal unit in the capital and how these could be reduced to decrease the burden on the neonatal unit.

Patients and Methods All full term neonatal admissions to the nn unit in Al-Bashir h, 1/1/2011-30/6/2011 were included, A special questionnare was filled which included the various characters of the group, sex distribution, birth weight, reason for admission, duration of hospitalisation and outcome.

Results During this period a total of 855 FTNN were admitted representing $47.6 \%$ of total admissions, $80 \%$ were admitted on day one, $60 \%$ were normal vaginal delivery. $90 \%$ were in born, respiratory distress was the main cause of admission, 32\%, IUGR $14.7 \%$, NNJ11.6\%,IODM8\%, ASPHYXIA 7\%,50\% were hospitalised for $1-3$ days, mortality rate was $5 \%, 62 \%$ of which were due to asphyxia, $30 \%$ were due to congenital malformations.

Conclusion FTNN represent a significant proportion of nn admissions the main reason for admission is respiratory distress, and the main reason for mortality is asphyxia, $50 \%$ are hospitalised for 3 or less days. a good nursery with intermediate care would decrease the load on the neonatal unit.

\section{6 PREDUCTAL TRANSCUTANEOUS OXYGEN SATURATION AT} BIRTH AFTER ELECTIVE CAESAREAN SECTION

doi:10.1136/archdischild-2012-302724.1306
'V Dal Cengio, ${ }^{2} \mathrm{M}$ Parotto, ${ }^{1 \mathrm{P}}$ Zanella, ${ }^{1} \mathrm{C}$ Zacchettin, ${ }^{1} \mathrm{~N}$ Rizzo, ${ }^{3} \mathrm{~F}$ Cavallin 'D Trevisanuto, ${ }^{4} \mathrm{~V}$ Zanardo. 'Children and Women's Health Department; ${ }^{2}$ Department of Anesthesia and Pharmacological Sciences, Padua University School of Medicine; 3/ndependent Statistician, Padova; "Neonatology Service, Abano Terme General Hospital, Abano Terme, Italy

Background The 2010 Neonatal Resuscitation Guidelines recommend preductal transcutaneous oxygen saturation $\left(\mathrm{SpO}_{2}\right)$ monitoring at birth in preterm and/or non reactive and/or hypotonic newborns. Previous studies have assessed $\mathrm{SpO}_{2}$ showing that $\mathrm{SpO}_{2}$ immediately after birth is higher in newborns by Vaginal Delivery (VD) vs. Caesarean Section (CS). This difference has never been investigated in newborns by Emergency CS (presence of labour) vs. Elective CS (absence of labour).

Objective To compare $\mathrm{SpO}_{2}$ in newborns by Emergency CS vs. Elective CS in the first minutes of life.

Methods The study included healthy newborns at term by Emergency CS, by Elective CS and by VD as control group. Infants receiving supplemental $\mathrm{O}_{2}$ or assisted ventilation were excluded. $\mathrm{SpO}_{2}$ was recorded for the first 10 minutes of life using a Masimo Radical-7 pulse oximeter probe (Masimo, Irvine, CA) applied to the right hand.

Results We studied 24 newborns by Emergency CS, 57 by Elective $\mathrm{CS}$ and 47 by VD. The $\mathrm{SpO}_{2}$ gradually improved during the first 10 minutes of life in all groups ( $\mathrm{p}$ per trend $<0,0001$ ). The $\mathrm{SpO}_{2}$ were similar in the tenth minute of life in all the 3 groups, but it was always higher in newborns by Emergency CS as well as by VD than in those by Elective CS from minute one to minute nine $(p<0.05)$.

Conclusions $\mathrm{SpO}_{2}$ in newborns by Emergency CS in the first minutes of life is higher than in those born by Elective CS as well as in newborns by VD vs. Elective CS.

\section{HIDDEN TOXICITY IN THE NICU: PHTHALATE EXPOSURE OF VERY LOW BIRTH WEIGHT INFANTS}

doi:10.1136/archdischild-2012-302724.1307

${ }^{1} \mathrm{~A}$ Demirel, ${ }^{1} \mathrm{~A}$ Coban, 'S Yildirim, ${ }^{2} \mathrm{C}$ Ekinci Dogan, ${ }^{2} \mathrm{R}$ Sanci, 'ZE Ince. 'Pediatrics, Division of Neonatology; '2 Istanbul University Istanbul Medical Faculty, Istanbul, Turkey

Aim To determine the exposure of VLBW infants to phthalates during their stay in the neonatal intensive care unit.

Method Preterm infants $(<32 \mathrm{wks}$ and/or $<1500 \mathrm{~g})$, who stayed in the NICU $>2$ wks and had at least one invasive procedure were included. Urine samples were collected in the first 3 days and every 2 weeks until discharge. Phthalate contents of the medical devices, urinary excretion of phthalate metabolites. (diethylhexylphthalate-DEHP, monoethylhexylphthalate-MEHP, monoethyloxohexylphthalate-MEOHP, monoethylhydroxyhexylphthalate-MEHHP) and their relation to exposure intensity, gestational age, birthweight and postnatal age were analysed.

Result Mean gestational age and birth weight of the patients $(\mathrm{n}=36)$ were $28.9 \pm 1.5 \mathrm{wks}$ and $1024 \pm 262 \mathrm{~g}$. DEHP was detected in umbilical catheters, intubation tubes, nasogastric tubes and nasal cannulas. Nasal cannulas had the highest content $(201.7 \mathrm{mg} / 0.5 \mathrm{~g})$. MEHHP was the most frequently detected metabolite $(81.4 \%)$ in the urine samples $(n=151)$ and its levels increased during the first 4 weeks (mean concentration: $319.5 \mathrm{ng} / \mathrm{ml}$ ), were higher in patients who had continuing need of invasive procedures after 2 wks (255.32 $\mathrm{ng} / \mathrm{ml}$ vs $65.85 \mathrm{ng} / \mathrm{ml}$ ), were significantly higher in the first urine samples of patients $<1000 \mathrm{~g}$ compared to those $\geq 1000 \mathrm{~g}(63.17 \pm 93.79$ $\mathrm{ng} / \mathrm{ml}$ vs $10.93 \pm 22.98 \mathrm{ng} / \mathrm{ml}, \mathrm{p}=0.001$ ).

Conclusion Phthalate metabolites could be detected in the urine samples of preterm infants very early after admission to the NICU. The levels were higher in the first weeks of intensive care when exposure intensity was highest and in babies $<1000 \mathrm{~g}$. Monoethylhydroxyhexylphthalate-MEHHP may be the most suitable biomarker of phthalate exposure. 